\title{
Metabolic control and bone health in adolescents with type 1 diabetes
}

\author{
Jill H Simmons ${ }^{1 *}$, Miranda Raines ${ }^{1}$, Kathryn D Ness ${ }^{2}$, Randon Hall ${ }^{1}$, Tebeb Gebretsadik ${ }^{3}$, Subburaman Mohan ${ }^{4}$ and \\ Anna Spagnoli ${ }^{5}$
}

\begin{abstract}
Background: Adults with type 1 diabetes (T1D) have decreased bone mineral density (BMD) and increased fracture risk, yet the etiologies remain elusive. Early detection of derangements in bone biomarkers during adolescence could lead to timely recognition. In adolescents with T1D, we evaluated the relationships between metabolic control, BMD, and bone anabolic and turnover markers.

Methods: Cross-sectional study of 57 adolescent subjects with T1D who had HbA1c consistently $\geq 9 \%$ (Poor Control, PC $n=27$ ) or $<9 \%$ (Favorable Control, FC $n=30$ ) for two years prior to enrollment. Subjects had T1DM for at least three years and were without diabetes complications, known celiac disease, or other chronic diseases.

Results: There were no differences between HbA1c groups in BMD, components of the IGF system, or 25hydroxyvitamin D status. The prevalence of 25 -hydroxyvitamin D abnormalities was similar to that seen in the general adolescent population. Few patients met the recommended dietary allowance (RDA) for vitamin D or calcium.

Conclusions: These data provide no evidence of association between degree of metabolic control and BMD in adolescents with T1D. Adolescents with T1D have a high prevalence of serum 25-hydroxyvitamin D abnormalities. Longitudinal studies are needed to evaluate the predictive value of vitamin $D$ abnormalities on fracture risk.
\end{abstract}

Keywords: bone mineral density, intact parathyroid hormone, insulin-like growth factor, type 1 diabetes, adolescent

\section{Introduction}

The effects of improved home blood glucose monitoring, pharmacotherapy, and educational interventions have led to a longer lifespan for patients with type 1 diabetes mellitus (T1D). However, bone health remains a problem for many with T1D, as adults with T1D have increased fracture risk and generalized osteoporosis $[1,2]$, and abnormalities in bone mineral density (BMD) have been reported in adolescents with T1D. The underlying mechanisms triggering the changes in BMD in patients with T1D are not well-known. Reports of the relationships between metabolic control, BMD, and bone marker parameters in patients with T1D have been conflicting $[3,4]$. Evaluations of bone disease in

\footnotetext{
* Correspondence: jill.h.simmons@vanderbilt.edu

'Department of Pediatrics, Division of Endocrinology and Diabetes,

Vanderbilt Children's Hospital, Nashville, TN, USA

Full list of author information is available at the end of the article
}

adults with T1D are generally complicated by the presence of other diabetic complications such as nephropathy, muscle insufficiency, or impaired vision that can affect bone disease. Early detection, prior to other diabetes complications, of derangements in bone markers can provide insight into the pathogenesis of bone disease in patients with T1D.

Bone health is dependent upon appropriate regulation of both anabolic and catabolic processes. Insulin-like growth factor I (IGF-I) is an anabolic regulator of bone metabolism, and BMD has been positively correlated with IGF-I levels in both human and animal studies [5-7]. IGF-I is decreased in patients with T1D, associated with the degree of metabolic control [8-10]. Patients with T1D have dysregulation of the growth hormone-IGF-I axis [9-11] and dysregulation of IGF binding proteins (IGFBP) $[9,11]$, which determine the tissue availability of IGF-I. Parathyroid hormone has both

\section{Biomed Central}


anabolic and catabolic effects on bone. Low, unaltered or elevated levels of intact parathyroid hormone (iPTH) have previously been reported in patients with T1D $[12,13]$. However, these studies evaluated few patients and included patients with important confounders such as diabetic nephropathy that may have led to secondary hyperparathyroidism. Aberrations in bone markers may be predictive of osteoporosis and fractures [14]. Bonespecific alkaline phosphatase, which is a bone formation marker reflective of osteoblastic activity, is lower in patients with T1D than controls [15]. In addition, urinary cross linked N-telopeptides of type I collagen (NTX), bone breakdown markers, are decreased in patients with T1D [16]. Bone turnover therefore is decreased in patients with T1D, although the etiologies are unclear.

Peak bone mass is attained by early adulthood [17], and therefore interference with this process in adolescence results in life-long complications. Evaluations of bone disease in adolescents with T1D are limited. This study was designed to evaluate whether in adolescents with T1D: 1) poor metabolic control is associated with reduced $\mathrm{BMD}$; 2) changes in biochemical bone parameters such as IGF-I system components, iPTH, bone turnover markers, and 25-hydroxyvitamin D are associated with metabolic control. We also hypothesized that adolescents with T1D would have a higher prevalence of vitamin D deficiency than the healthy adolescent population.

\section{Materials and methods Participants}

Adolescents (ages 13-18 years) with T1D for $\geq 3$ years were recruited from the pediatric clinic in the Eskind Diabetes Center at Vanderbilt Medical Center. All participants were diagnosed with T1D by a pediatric endocrinologist. The study was conducted in accordance with the Declaration of Helsinki and was approved by the Vanderbilt University Medical Center Institutional Review Board. Informed consent was obtained from each participant's parent/legal guardian, and informed assent was obtained from each participant prior to beginning the study. Participants were categorized by the degree of glucose control. Poor control (PC) was defined as all (must have a minimum of 3) HbA1c measurements $\geq 9 \%$ and favorable control (FC) was defined as all HbA1c measurements $<9 \%$ during the previous 2 years. Exclusion criteria were: presence of microalbuminuria, retinopathy or neuropathy; pre-existing bone disease, cystic fibrosis or celiac disease, eating disorder, estro-progesterone or testosterone treatment including oral contraceptives, smoking, pregnancy, amenorrhea, polycystic ovarian syndrome as diagnosed by a pediatric endocrinologist based upon irregular menses as well as hirsutism and/or biochemical evidence of androgen excess, obesity [body mass index (BMI) > 95th percentile for age and sex], short stature $(<3$ rd percentile for age and sex), or delayed/precocious puberty.

\section{Anthropometric Evaluation}

Height and weight were obtained, and body mass index was calculated based on the following formula: weight (kg)/height $(\mathrm{m})^{2}$.

\section{Response variables}

\section{Bone measurements}

The primary dependent variable was BMD measured by DEXA scan.

Total BMD, lumbar spine (L2-L4) BMD, L2-L4 width, and femoral neck BMD were determined by dual energy radiographic absorptiometry (DEXA, GE Healthcare, Lunar iDEXA, Tube model 40782). Prior to September 2007, DEXA scans were performed using the GE Healthcare Lunar Model 8743. Lumbar (L2-L4) BMD and L2-L4 width were used to determine bone mineral apparent density (BMAD, grams per cubic centimeter), which was calculated based on the following formula: BMD (L2-L4) $\times(4 /[$ pi x width]) [18]. Results were expressed as z-scores for total body BMD, lumbar BMD, BMAD, and femoral neck BMD. Z-scores were calculated using the means and SD reported for age and gender [19]. Serum pregnancy tests were negative on all females prior to DEXA scan.

\section{Laboratory Evaluation}

Other dependent variables included components of the IGF system, bone turnover makers, and serum 25hydroxyvitamin D levels. Venous blood samples were collected after an overnight fast (approximately 10 hours). Participants received their usual evening insulin glargine dose the night prior or were continued on their insulin pump at the usual basal rate. For each participant, serum for IGF-I, IGFBP-3 (insulin-like growth factor binding protein 3), IGFBP-4, IGFBP-5, iPTH, bonespecific alkaline phosphatase (BAP), total 25-hydroxyvitamin D, calcium, phosphorus, and creatinine were obtained. Urine was collected for 24 hours at home prior to arrival for analysis for cross linked N-telopeptides of type I collagen (NTX), creatinine, calcium, and phosphorus.

\section{Diet diary}

Subjects were asked to keep a diet diary for 72 hours prior to the study visit, in order to ascertain information regarding dietary vitamin $\mathrm{D}$ and calcium intake. Each subject was instructed to record type of food/beverage and amount consumed in as much detail as possible. Verbal and written instructions were given to each subject and his/her parents when consented for the study, and logsheets were provided for each subject. The 
information from these diet diaries was placed into the Nutrition Data System for Research (NDSR, University of Minnesota), and an analysis of calcium and vitamin D intake per day was obtained.

\section{Exposure variable}

The primary independent variable was the average of 3or more consistent levels of HbA1c in the 2 years prior to enrollment. Subjects were assigned either to the poor control (PC) group (HbA1c $\geq 9 \%$ ) or the favorable control group (FC) $(\mathrm{HbA} 1 \mathrm{c}<9 \%)$. Subjects who had HbA1c values in both categories during the two years prior to potential study enrollment were excluded. The enrollment plan included that an equal number $( \pm 10 \%)$ of subjects would be enrolled in the two metabolic groups. This targeted enrollment by HBA1c was to ascertain that subjects in poor control were represented in study.

\section{Assay methods}

HbA1c was measured by point-of-care immunoassay using the DCA Vantage Analyzer (Siemens Healthcare Diagnostics, Deerfield, IL, USA). Serum concentration of total IGFI was measured by radioimmunoassay (RIA) (ALPCO Diagnostics, Salem, NH, USA). Inter- and intra-assay coefficients of variation were $3.4-4.2 \%$ and $2.6-4.1 \%$, respectively. Serum IGFBP-3 was measured by radioimmunoassay (RIA) using rabbit polyclonal antiserum and human recombinant IGFBP-3 as standard and tracer [20]. Serum IGFBP-4 was measured by a specific RIA using recombinant human IGFBP-4 expressed in Escherichia coli as antigen, tracer and standard [21]. Antibodies against human IGFBP-4 were developed in guinea pigs as described previously [21]. Inter-and intra-assay variations were less than $8 \%$. There was no cross-reactivity with other IGFBPs. Serum IGFBP-5 was measured by a specific RIA using recombinant human IGFBP-5 as antigen, tracer and standard as described [22]. There was no cross-reactivity with other IGFBPs. Inter-and intra-assay variations were less than $8 \%$. Cross-linked Ntelopeptides in urine were measured by chemiluminescent immunoassay (ARUP Laboratories, Salt Lake City, UT, USA). Intact PTH was measured using the Roche Cobas electrochemiluminescence assay, BAP was measured by the immunoenzymatic assay Access Ostase, and total 25hydroxyvitamin D was measured using Liquid Chromatography-Tandem Mass Spectrometry (LC-MS/MS) (Mayo Medical Laboratories, Rochester, MN, USA). The criteria used to define vitamin D sufficiency, insufficiency, and deficiency were 25-hydroxyvitamin D levels $\geq 30 \mathrm{ng} / \mathrm{mL}, 15-29$ $\mathrm{ng} / \mathrm{mL}$, and $<15 \mathrm{ng} / \mathrm{mL}$, respectively, as was recently reported [23].

\section{Statistical methods}

Clinical and demographic variables are presented as number and percent or medians and interquartile ranges $[\mathrm{IQR}]$. Categorical variables were compared by HbA1c degree of control group with $\chi^{2}$ test and continuous variables with Wilcoxon rank sum test. Spearman correlation coefficients (rho) were used to assess the correlation of continuous BMD measures, components of the IGF system, bone turnover markers, vitamin $\mathrm{D}$ and calcium intake, age, and HbA1c. We assessed for the adjusted association between BMD measures, components of the IGF system, bone turnover markers, vitamin $\mathrm{D}$ and calcium intake and age with $\mathrm{HbA1c}$ as an independent variable with multiple linear regression analyses. Multivariable linear regression assumptions of normality of residuals were checked and were met. Covariates for adjustment were chosen a priori and included age, gender and race. All reported $p$ values are unadjusted for multiple tests. All analyses used a 5\% two-sided significance level and were performed with $\mathrm{R}$ version 2.10 .10 http://www.rproject.org. To compare the prevalence of vitamin $\mathrm{D}$ status with published NHANES study report[23], we calculated the proportion of subjects who were insufficient and deficient in 25-hydroxyvitamin $\mathrm{D}$ by gender and calculated the $95 \%$ confidence interval (CI) for binomial proportion using the Wilson method. The Wilson method was used as it works better for calculation of $95 \%$ CI with small samples and extreme probability (approaching 1 or 0) [24].

\section{Results}

\section{Demographic characteristics}

The study population included 57 participants, 30 in the FC group and 27 in the PC group (stable HbA1c during the 2 years prior to study participation). There were no significant differences between groups in age, gender, duration of diabetes, or anthropometrics (Table 1). As expected based on selection criteria, the average HbA1c during the two years prior to the study in the PC group was higher than that in the FC group.

\section{BMD, bone markers, and components of the IGF system in $\mathrm{FC}$ and $\mathrm{PC}$ groups}

The FC group had a higher iPTH level $[30.5 \mathrm{pg} / \mathrm{ml}$ $(21.8,37.8)]$ compared with the PC group $[19 \mathrm{pg} / \mathrm{ml}$ $(15,31)], p=0.04$. The FC group also had higher urine $\mathrm{n}$-telopeptides (NTX) than the PC group [238 $\mathrm{nM} \mathrm{BCE} / \mathrm{mM}$ creat $(98,366)$ vs $56 \mathrm{nM} \mathrm{BCE} / \mathrm{mM}$ creat $(41,311), \mathrm{p}=0.03]$ and a lower urine $\mathrm{Ca} / \mathrm{Cr}$ than the $\mathrm{PC}$ group $[0.07(0.05,0.15)$ vs $0.14(0.09,0.21), \mathrm{p}=$ 0.02 ], consistent with higher iPTH levels (Table 2). There were no differences between groups in measurements of BMD, IGFI or IGFBPs, BAP, serum calcium, serum creatinine, eGFR, or 25-hydroxyvitamin D levels. 
Table 1 Characteristics of subjects by metabolic control, results shown as median and [IQR] interquartile range.

\begin{tabular}{lccc}
\hline & $\begin{array}{c}\text { Favorable Control } \\
(\mathbf{n}=\mathbf{3 0})\end{array}$ & $\begin{array}{c}\text { Poor Control } \\
(\mathbf{n}=\mathbf{2 7})\end{array}$ & $\boldsymbol{p}$ value* \\
\hline HbA1C (\%) & $\mathbf{7 . 7}[\mathbf{7 . 3}, \mathbf{7 . 9}]$ & $\mathbf{1 0 . 3}[\mathbf{9 . 9}, \mathbf{1 1 . 4}]$ & $* *$ \\
\hline Age (yrs) & $15.2[14.3,16.1]$ & $16.4(15.1,17.8)$ & 0.05 \\
\hline Gender (\% female) & $37 \%$ & $59 \%$ & 0.42 \\
\hline Race (\% Caucasian) & $87 \%[26 / 30]$ & $81 \%[21 / 26]$ & 0.55 \\
\hline Duration DM (yrs) & $6.5[4.8,8.0]$ & $6.5[5.5,9.5]$ & 0.40 \\
\hline Height $(\mathrm{cm})$ & $169.8[158.6,178.1]$ & $163.2[16.03,165.7]$ & 0.22 \\
\hline Weight $(\mathrm{kg})$ & $68.5[55.4,74.0]$ & $67.5[59.0,77.5]$ & 0.91 \\
\hline BMl $\left(\mathrm{kg} / \mathrm{m}^{2}\right)$ & $22.8[20.4,27.5]$ & $25.0[21.4,27.9]$ & 0.35 \\
\hline
\end{tabular}

*Wilcoxon rank sum test for continuous variables or $\chi^{2}$ test for categorical variables.

** Groups were defined based on $\mathrm{HbA} 1 \mathrm{c}$

Relationship between metabolic control and BMD, bone markers, IGF system components and vitamin D/calcium intake

Univariate analyses (Table 3 ) demonstrated a positive correlation between HbA1c and \% body fat (rho = 0.30, $\mathrm{p}=0.02$ ) and urine $\mathrm{Ca} / \mathrm{Cr}$ ( rho $=0.27, \mathrm{p}=0.047$ ) and negative correlations between HbA1c and NTX (rho = -0.36, $\mathrm{p}=0.01$ ), intact PTH (rho $=-0.28, \mathrm{p}=0.04$ ), and serum creatinine (rho $=-0.27, \mathrm{p}=0.04$ ). There were no other significant correlations between HbA1c and any of the other study variables. After controlling for age, sex, and race, there was a positive association between HbA1c and serum phosphorus and a negative association between HbA1c and serum creatinine that were statistically significant. There were no associations between HbA1c and BMD, bone turnover markers, components of the IGF system, serum 25-hydroxyvitamin D, serum calcium, or dietary intake of calcium and vitamin $\mathrm{D}$.

\section{Dietary Intake of vitamin D and calcium}

Subjects with T1D who have favorable metabolic control report consuming a similar amount of vitamin $\mathrm{D}$ and calcium as those who have poor metabolic control (Table 2). Only $12 \%(3 / 25)$ of the total subgroup with intake data reported consuming the recommended daily allowance (RDA) of vitamin D (400 IU/day at the time of the study), and 16\% (4/25) of the total subgroup reported consuming the RDA for calcium (1300 mg/ day), with no differences between groups (18\% vs $12 \%$, p $=0.74)$. When evaluated with the Institute of Medicine's 2011 RDA of 600 IU vitamin D/day [25], only 1 subject reported consuming this amount.

Table 2 Clinical and biochemical features of subjects with T1D

\begin{tabular}{|c|c|c|c|c|}
\hline & $\mathrm{n}$ & $\mathrm{FC}(\mathrm{n}=30)$ & $P C(n=27)$ & $p$ valuet \\
\hline Lumbar spine BMD* & 56 & $0.01(-1.14,1.07)$ & $-0.46(-0.82,0.37)$ & 0.58 \\
\hline Volumetric lumbar spine (BMAD)* & 56 & $0.05(-0.63,0.69)$ & $-0.14(-0.48,0.57)$ & 0.83 \\
\hline Femoral neck BMD* & 56 & $0.12(-1.23,0.98)$ & $-0.48(-1.19,1.39)$ & 0.66 \\
\hline Total body BMD* & 56 & $0.46(-1.27,1.35)$ & $-0.03(-1.1,0.72)$ & 0.66 \\
\hline$\%$ body fat & 56 & $28.7(16.7,35.3)$ & $33.7(20.2,40)$ & 0.22 \\
\hline IGF-1 (ng/mL) & 56 & $564(430,644)$ & $488(402,603)$ & 0.29 \\
\hline IGF BP-3 $(\mu \mathrm{g} / \mathrm{L})$ & 54 & $2883(2448,3060)$ & $2901(2676,3436)$ & 0.36 \\
\hline IGF BP-4 ( $\mu \mathrm{g} / \mathrm{L})$ & 54 & $398.5(334.8,439.2)$ & $415.5 \pm 57.9$ & 0.17 \\
\hline IGF BP-5 $(\mu \mathrm{g} / \mathrm{L})$ & 54 & $346.0(300.8,384.2)$ & $316.5(273.2,447.8)$ & 0.55 \\
\hline NTX (nM BCE/mM creat) & 54 & $238(98,366)$ & $56(41,311)$ & 0.03 \\
\hline Bone-Specific Alkaline Phosphatase (ug/L) & 53 & $34(23,63)$ & $19(14.5,49.5)$ & 0.09 \\
\hline Intact PTH $(\rho g / m L)$ & 53 & $30.5(21.8,37.8)$ & $19(15,31)$ & 0.04 \\
\hline Serum 25-hydroxyvitamin D (ng/mL) & 52 & $31(21,37)$ & $32(24,38.5)$ & 0.76 \\
\hline Serum Calcium (mg/dL) & 56 & $9.4(9.3,9.7)$ & $9.4(9.2,9.6)$ & 0.99 \\
\hline Serum Phosphorus (mg/dL) & 56 & $4.4(4.1,5.0)$ & $4.8(4.3,5.2)$ & 0.21 \\
\hline Serum creatinine $(\mathrm{mg} / \mathrm{dL})$ & 56 & $0.75(0.63,0.8)$ & $0.7(0.6,0.8)$ & 0.22 \\
\hline eGFR estimation (ml/min) & 56 & $137.5(122.7,149.8)$ & $141.8(118.2,166.4)$ & 0.72 \\
\hline $\mathrm{uCa} / \mathrm{uCr}$ & 54 & $0.07[0.05,0.15]$ & $0.14[0.09,0.21]$ & 0.02 \\
\hline uPhos/uCr & 54 & $0.80[0.64,0.92]$ & $0.90[0.72,1.0]$ & 0.22 \\
\hline Average vitamin D intake/day (IU) & 25 & $173(128,246)$ & $168(122,246)$ & 1 \\
\hline Average calcium intake/day (mg) & 25 & $872(651,1136)$ & $686(574,927)$ & 0.46 \\
\hline
\end{tabular}

Items in bold $\mathrm{p}<0.05$.

+ Wilcoxon rank sum test for comparison of continuous variables

* z-scores

Abbreviations: FC: Favorable Control, PC: Poor Control, BMD: bone mineral density, BMAD: bone mineral apparent density, eGFR (estimated glomerular filtration rate) 
Table 3 Association between HbA1c and bone mineral density measurements, components of the IGF system, bone turnover markers, and dietary intake of calcium and vitamin D

\begin{tabular}{|c|c|c|c|}
\hline & Spearman correlation coefficient & $p$ value* & Adjusted $p$ value ** \\
\hline Age & 0.24 & 0.08 & \\
\hline Lumbar Spine BMD † & -0.12 & 0.37 & 0.63 \\
\hline Volumetric Lumbar Spine † (BMAD) & -0.041 & 0.76 & 0.85 \\
\hline Femoral neck BMD † & -0.056 & 0.68 & 0.24 \\
\hline Total body BMD † & -0.086 & 0.53 & 0.87 \\
\hline$\%$ Body fat & 0.30 & 0.02 & 0.66 \\
\hline IGF-I (ng/ml) & -0.15 & 0.27 & 0.92 \\
\hline IGFBP3 ( $\mu \mathrm{g} / \mathrm{L})$ & 0.13 & 0.37 & 0.33 \\
\hline IGFBP4 ( $\mu \mathrm{g} / \mathrm{L})$ & 0.23 & 0.10 & 0.1 \\
\hline IGFBP5 ( $\mu \mathrm{g} / \mathrm{L})$ & -0.09 & 0.52 & 0.65 \\
\hline NTX (nM BCE/mM creat) & -0.36 & 0.01 & 0.73 \\
\hline Bone-specific alkaline phosphatase $(\mu \mathrm{g} / \mathrm{L})$ & -0.26 & 0.06 & 0.81 \\
\hline Intact PTH ( $\mathrm{gg} / \mathrm{ml})$ & -0.28 & 0.04 & 0.2 \\
\hline Serum 25-hydroxyvitamin D (ng/ml) & -0.047 & 0.74 & 0.89 \\
\hline Serum Calcium (ml/dL) & 0.15 & 0.28 & 0.19 \\
\hline Serum Phosphorus (mg/dL) & 0.2 & 0.14 & 0.01 \\
\hline Serum creatinine $(\mathrm{mg} / \mathrm{dL})$ & -0.27 & 0.04 & 0.007 \\
\hline $\mathrm{UCa} / \mathrm{uCr}$ & 0.27 & 0.047 & 0.05 \\
\hline uPhos/uCr & 0.22 & 0.1 & 0.37 \\
\hline Average vitamin D intake/day (IU) & -0.09 & 0.67 & 0.55 \\
\hline Average calcium intake/day (mg) & -0.13 & 0.55 & 0.42 \\
\hline
\end{tabular}

Items in bold $\mathrm{p}<0.05$.

*Spearman correlation coefficient $\mathrm{p}$ value; ${ }^{* *} \mathrm{p}$ value adjusted for age, race, and gender; $† \mathrm{z}$-scores

Hydroxyvitamin D status There were no differences between groups in serum 25-hydroxyvitamin D levels (Table 2), with $14 \%$ of the FC group deficient (25-hydroxyvitamin D levels $<15 \mathrm{ng} / \mathrm{ml}$ ) and 31\% insufficient (25hydroxyvitamin D levels $15-29 \mathrm{ng} / \mathrm{ml}$ ) and $13 \%$ of the PC group deficient and $35 \%$ insufficient in serum 25 -hydroxyvitamin $\mathrm{D}, \mathrm{p}=0.96$. Together, there were no differences between subjects with T1D and the normal adolescent population [23] in the prevalence of 25-hydroxyvitamin D deficiency, as $11 \%$ (95\%CI: $2.9 \%, 31.4 \%)$ of girls and $0 \%$ (95\%CI: $0,13.3 \%$ ) of boys with T1D were deficient in $25-$ hydroxyvitamin D, compared with $5 \%$ and $3 \%$ of the normal adolescent population, respectively. Thirty-two percent of girls (95\%CI: $15.4 \%, 54.0 \%)$ and $40 \%$ (95\%CI: $23.4 \%, 59.2 \%$ ) of boys were insufficient in 25-hydroxyvitamin D, compared with $57 \%$ and $63 \%$, respectively, of the general adolescent population. When using the 2011 Institute of Medicine Report's definition of vitamin D inadequacy [25], 21\% of the FC group and 17\% of the PC group had 25-hydroxyvitamin D levels $<20 \mathrm{ng} / \mathrm{ml}, \mathrm{p}=0.76$.

\section{Discussion}

This study addresses whether metabolic control has an effect on bone health in patients with T1D who have not yet achieved peak bone mass. Adolescents with T1D in consistently poor metabolic control appear to have lower iPTH levels than a group of adolescents with T1D in favorable metabolic control, although this association was attenuated when adjusted for age, gender and race. After adjustment, urine calcium is associated with metabolic control, consistent with lower iPTH levels. We also explored the prevalence of 25-hydroxyvitamin D abnormalities in adolescents with T1D, as vitamin D abnormalities have been increasingly recognized as a significant health problem both for healthy patients and those with chronic illnesses [26]. Adolescents with T1D have significant 25-hydroxyvitamin D abnormalities, but these abnormalities are not more prevalent than in the general adolescent population.

Poor bone health is a significant problem for many adults with T1D, as is demonstrated by a two-fold increase in fracture risk in the lumbar spine, femoral neck, and distal radius [1]. Women with T1D have more than a 10-fold increase in risk of hip fractures compared with age-matched controls [2]. Almost 20\% of patients with T1D ages 20-56 years meet criteria for osteoporosis [27], which is a debilitating illness that impairs functionality and quality of life [28]. However, 
the etiologies of decreased BMD in adults with T1D have been unclear $[29,30]$. The mechanisms of osteoporosis associated with T1D differ from the development of osteoporosis associated with aging [31], and several potential mechanisms have been proposed, including effects of advanced glycation end products in bone collagen [32], increased urinary excretion of calcium, phosphate and magnesium [33], inflammatory cytokines [34], low levels of iPTH [12], diabetic microangiopathy with reduced blood flow to bone [35], decreased bone resorption [16], decreased bone formation [36], and vitamin D deficiency [37]. We sought to evaluate whether poor metabolic control during adolescence is associated with abnormal bone health.

Previous studies investigating the role of metabolic control and BMD in patients with T1D have been limited by older BMD measurement methods which may be inaccurate, limited knowledge in the consistency of patients' actual metabolic control (many studies use only a single HbA1c measurement as the index of metabolic control), and confounding factors affecting BMD such as the use of oral contraceptives. In this study, we controlled confounding factors and found no correlations between metabolic control and BMD, similar to others [3,38,39], but differing from some [4]. Although subjects had stable diabetes control for two years prior to the study, two years of poor diabetes control may not be long enough to lead to changes in BMD demonstrated by DEXA scans in adolescents.

The role of IGF-I as a critical anabolic regulator of BMD is clearly demonstrated in animal studies in which genetic manipulation of the IGF system led to osteopenia [7]. In humans, cross-sectional and cohort studies in various populations, including subjects from the Framingham Heart Study, have demonstrated a strong correlation between serum levels of IGF-I and BMD $[6,40]$. Dysregulation of the IGF-I/IGFBP system has been reported in patients with $\mathrm{T} 1 \mathrm{D}$ [9-12,32]. We found no associations between metabolic control and components of the IGFI system, although other studies have reported that IGF-I levels correlate with metabolic control [11]. As we did not have a control group of healthy subjects, IGFI levels may be too low within a population of T1D patients to detect significant differences.

Only $35 \%$ of healthy non-Hispanic white adolescents are sufficient in 25-hydroxyvitamin D [23], which plays an important role in the maintenance of bone health. Similar to recent studies, we found a significant prevalence of 25-hydroxyvitamin D abnormalities in adolescents with T1D $[37,41]$, but we did not find a difference in 25-hydroxyvitamin D status between adolescents with T1D and the normal adolescent population [23]. However, the proportions of vitamin D sufficiency status by gender were limited by small numbers which resulted in proportions with wide confidence intervals. There is not enough evidence to support that metabolic control plays a role in vitamin D status, and other risk factors need to be evaluated.

Only one subject reported consuming the current RDA for vitamin D, with $16 \%$ consuming the RDA for calcium. This is not different from the healthy adolescent population, as previous data from NHANES III (1988-1994) demonstrated that only $53-63 \%$ of all US children consume at least 200 IU of vitamin D per day from diet and/or supplementation. (200 IU was reported in this paper because it was considered Adequate Intake for vitamin D at that time) [42]. This is of particular concern for adolescent patients with T1D, as vitamin D and calcium intake are modifiable factors that have a significant impact on BMD.

Our study had several limitations. We stratified by design the subjects into poor and favorable metabolic control groups, and we could have missed relationships between HbA1c and study variables due to a lack of a full continuous spectrum of HbA1c values. We did not have a control group of non-diabetic patients. Also, we did not obtain information regarding exercise and specifics regarding pubertal development, which clearly have an effect on BMD and bone turnover. However, we attempted to address this issue by excluding patients with obesity as well as known pubertal delay, amenorrhea, or polycystic ovarian syndrome.

In summary, metabolic control is not associated with BMD as evaluated by DEXA in this adolescent population with T1D, and bone anabolic and turnover markers are not affected by metabolic control, once age, gender, and race are taken into account. Adolescents with T1D are frequently vitamin D insufficient, which is likely also playing an important role in bone metabolism.

\section{Abbreviations}

T1D: type 1 diabetes mellitus; HbA1c: hemoglobin A1c; PC: poor control; FC: favorable control; NTX: urinary cross linked N-telopeptides of type I collagen; BAP: bone-specific alkaline phosphatase; IGF-I (insulin-like growth factor I).

\section{Acknowledgements}

Supported by Vanderbilt CTSA grant 1 UL1 RR024975 from the National Center for Research Resources (National Institutes of Health), Vanderbilt Clinical Nutrition Research Unit grant, an unrestricted educational grant from Genentech's Center for Clinical Research, and National Institutes of Health AR-048139.

\section{Author details}

'Department of Pediatrics, Division of Endocrinology and Diabetes, Vanderbilt Children's Hospital, Nashville, TN, USA. ${ }^{2}$ Department of Pediatrics, Division of Pediatric Endocrinology, Seattle Children's Hospital, Seattle, WA, USA. ${ }^{3}$ Department of Biostatistics, Vanderbilt University Medical Center, Nashville, TN, USA. 'Musculoskeletal Disease Center, Jerry L Pettis VA Medical Center, and Departments of Medicine and Biochemistry, Loma Linda University, Loma Linda, CA, USA. ${ }^{5}$ Department of Pediatrics, Division of Pediatric Endocrinology, University of North Carolina at Chapel Hill, Chapel Hill, NC, USA. 


\section{Authors' contributions}

JS made substantial contributions to study design, data acquisition, analysis and interpretation of data, and drafted the manuscript. MR, KN, RH, and AS contributed substantially to study design, subject recruitment, data acquisition, and analysis and interpretation of the data. TG contributed through statistical analysis and interpretation of the data. SM contributed through study design and data acquisition. All authors critically revised the manuscript for important intellectual content and approved the final version of the manuscript.

\section{Competing interests}

The authors declare that they have no competing interests.

Received: 11 July 2011 Accepted: 26 October 2011

Published: 26 October 2011

\section{References}

1. Hofbauer LC, Brueck CC, Singh SK, Dobnig H: Osteoporosis in patients with diabetes mellitus. J Bone Miner Res 2007, 22:1317-1328.

2. Nicodemus KK, Folsom AR: Type 1 and type 2 diabetes and incident hip fractures in postmenopausal women. Diabetes Care 2001, 24:1192-1197.

3. Hamilton EJ, Rakic V, Davis WA, Chubb SA, Kamber N, Prince RL, et al: Prevalence and predictors of osteopenia and osteoporosis in adults with Type 1 diabetes. Diabet Med 2009, 26:45-52.

4. Heilman K, Zilmer M, Zilmer K, Tillmann V: Lower bone mineral density in children with type 1 diabetes is associated with poor glycemic control and higher serum ICAM-1 and urinary isoprostane levels. J Bone Miner Metab 2009, 27:598-604.

5. Zhao G, Monier-Faugere MC, Langub MC, Geng Z, Nakayama T, Pike JW, et al: Targeted overexpression of insulin-like growth factor I to osteoblasts of transgenic mice: increased trabecular bone volume without increased osteoblast proliferation. Endocrinology 2000, 141:2674-2682.

6. Langlois JA, Rosen CJ, Visser M, Hannan MT, Harris T, Wilson PW, et al: Association between insulin-like growth factor I and bone mineral density in older women and men: the Framingham Heart Study. J Clin Endocrinol Metab 1998, 83:4257-4262.

7. Yakar S, Rosen CJ, Beamer WG, ckert-Bicknell CL, Wu Y, Liu JL, et al: Circulating levels of IGF-1 directly regulate bone growth and density. J Clin Invest 2002, 110:771-781.

8. Dills DG, Allen C, Palta M, Zaccaro DJ, Klein R, D'Alessio D: Insulin-like growth factor-l is related to glycemic control in children and adolescents with newly diagnosed insulin-dependent diabetes. J Clin Endocrinol Metab 1995, 80:2139-2143.

9. Spagnoli A, Chiarelli F, Vorwerk P, Boscherini B, Rosenfeld RG: Evaluation of the components of insulin-like growth factor (IGF)-IGF binding protein (IGFBP) system in adolescents with type 1 diabetes and persistent microalbuminuria: relationship with increased urinary excretion of IGFBP-3 18 kD N-terminal fragment. Clin Endocrinol (Oxf) 1999, 51:587-596.

10. Strasser-Vogel B, Blum WF, Past R, Kessler U, Hoeflich A, Meiler B, et al: Insulin-like growth factor (IGF)-I and -II and IGF-binding proteins-1, -2, and -3 in children and adolescents with diabetes mellitus: correlation with metabolic control and height attainment. J Clin Endocrinol Metab 1995, 80:1207-1213.

11. Moyer-Mileur LJ, Slater H, Jordan KC, Murray MA: IGF-1 and IGF-binding proteins and bone mass, geometry, and strength: relation to metabolic control in adolescent girls with type 1 diabetes. J Bone Miner Res 2008, 23:1884-1891

12. Saggese G, Bertelloni S, Baroncelli Gl, Federico G, Calisti L, Fusaro C: Bone demineralization and impaired mineral metabolism in insulin-dependent diabetes mellitus. A possible role of magnesium deficiency. Helv Paediatr Acta 1989, 43:405-414.

13. Jehle PM, Jehle DR, Mohan S, Bohm BO: Serum levels of insulin-like growth factor system components and relationship to bone metabolism in Type 1 and Type 2 diabetes mellitus patients. J Endocrinol 1998, 159:297-306.

14. Garnero P, Hausherr E, Chapuy MC, Marcelli C, Grandjean H, Muller C, et al: Markers of bone resorption predict hip fracture in elderly women: the EPIDOS Prospective Study. J Bone Miner Res 1996, 11:1531-1538.

15. Lumachi F, Camozzi V, Tombolan V, Luisetto G: Bone mineral density, osteocalcin, and bone-specific alkaline phosphatase in patients with insulin-dependent diabetes mellitus. Ann N Y Acad Sci 2009, 1173(Suppl 1):E64-E67.

16. Gunczler P, Lanes R, Paz-Martinez V, Martins R, Esaa S, Colmenares V, et al: Decreased lumbar spine bone mass and low bone turnover in children and adolescents with insulin dependent diabetes mellitus followed longitudinally. J Pediatr Endocrinol Metab 1998, 11:413-419.

17. Lehtonen-Veromaa MK, Mottonen TT, Nuotio IO, Irjala KM, Leino AE, Viikari JS: Vitamin $D$ and attainment of peak bone mass among peripubertal Finnish girls: a 3-y prospective study. Am J Clin Nutr 2002, 76:1446-1453.

18. Boot AM, De MK-S, Pols HA, Krenning EP, Drop SL: Bone mineral density and body composition before and during treatment with gonadotropinreleasing hormone agonist in children with central precocious and early puberty. J Clin Endocrinol Metab 1998, 83:370-373.

19. van dS, de Ridder MA, Boot AM, Krenning EP, de Muinck KeizerSchrama SM: Reference data for bone density and body composition measured with dual energy $\mathrm{X}$ ray absorptiometry in white children and young adults. Arch Dis Child 2002, 87:341-347.

20. Nakao Y, Hilliker S, Baylink DJ, Mohan S: Studies on the regulation of insulin-like growth factor binding protein 3 secretion in human osteosarcoma cells in vitro. J Bone Miner Res 1994, 9:865-872

21. Honda Y, Landale EC, Strong DD, Baylink DJ, Mohan S: Recombinant synthesis of insulin-like growth factor-binding protein-4 (IGFBP-4): Development, validation, and application of a radioimmunoassay for IGFBP-4 in human serum and other biological fluids. J Clin Endocrinol Metab 1996, 81:1389-1396.

22. Mohan S, Libanati C, Dony C, Lang K, Srinivasan N, Baylink DJ: Development, validation, and application of a radioimmunoassay for insulin-like growth factor binding protein-5 in human serum and other biological fluids. J Clin Endocrinol Metab 1995, 80:2638-2645.

23. Kumar J, Muntner P, Kaskel FJ, Hailpern SM, Melamed ML: Prevalence and Associations of 25-Hydroxyvitamin D Deficiency in US Children: NHANES 2001-2004. Pediatrics 2009.

24. Wilson EB: Probable Inference, the Law of Succession, and Statistical Inference. J Am Statistical Association 1927, 22:209-212.

25. Institute of Medicine 2011 Dietary reference intakes for calcium and vitamin D. Washington, DC, The National Academies Press. Ref Type: Report; 2011.

26. Ashraf A, Alvarez J, Saenz K, Gower B, McCormick K, Franklin F: Threshold for effects of vitamin $D$ deficiency on glucose metabolism in obese female African-American adolescents. J Clin Endocrinol Metab 2009, 94:3200-3206.

27. Munoz-Torres M, Jodar E, Escobar-Jimenez F, Lopez-Ibarra PJ, Luna JD: Bone mineral density measured by dual X-ray absorptiometry in Spanish patients with insulin-dependent diabetes mellitus. Calcif Tissue Int 1996, 58:316-319.

28. Fechtenbaum J, Cropet C, Kolta S, Horlait S, Orcel P, Roux C: The severity of vertebral fractures and health-related quality of life in osteoporotic postmenopausal women. Osteoporos Int 2005, 16:2175-2179.

29. Valerio G, del PA, Esposito-del PA, Buono P, Mozzillo E, Franzese A: The lumbar bone mineral density is affected by long-term poor metabolic control in adolescents with type 1 diabetes mellitus. Horm Res 2002, 58:266-272.

30. Heap J, Murray MA, Miller SC, Jalili T, Moyer-Mileur L: Alterations in bone characteristics associated with glycemic control in adolescents with type 1 diabetes mellitus. J Pediatr 2004, 144:56-62.

31. McCabe LR: Understanding the pathology and mechanisms of type I diabetic bone loss. J Cell Biochem 2007, 102:1343-1357.

32. Paul RG, Bailey AJ: Glycation of collagen: the basis of its central role in the late complications of ageing and diabetes. Int I Biochem Cell Biol 1996, 28:1297-1310.

33. Ward DT, Yau SK, Mee AP, Mawer EB, Miller CA, Garland HO, et al: Functional, molecular, and biochemical characterization of streptozotocin-induced diabetes. J Am Soc Nephrol 2001, 12:779-790.

34. Manolagas SC, Jilka RL: Bone marrow, cytokines, and bone remodeling. Emerging insights into the pathophysiology of osteoporosis. N Engl J Med 1995, 332:305-311.

35. McNair P, Christensen MS, Christiansen C, Madsbad S, Transbol I: Is diabetic osteoporosis due to microangiopathy? Lancet 1981, 1:1271. 
36. Bouillon R, Bex M, Van HE, Laureys J, Dooms L, Lesaffre E, et al: Influence of age, sex, and insulin on osteoblast function: osteoblast dysfunction in diabetes mellitus. J Clin Endocrinol Metab 1995, 80:1194-1202.

37. Svoren BM, Volkening LK, Wood JR, Laffel LM: Significant vitamin D deficiency in youth with type 1 diabetes mellitus. J Pediatr 2009, 154:132-134

38. Karaguzel G, Akcurin S, Ozdem S, Boz A, Bircan I: Bone mineral density and alterations of bone metabolism in children and adolescents with type 1 diabetes mellitus. J Pediatr Endocrinol Metab 2006, 19:805-814.

39. Pascual J, Argente J, Lopez MB, Munoz M, Martinez G, Vazquez MA, et al: Bone mineral density in children and adolescents with diabetes mellitus type 1 of recent onset. Calcif Tissue Int 1998, 62:31-35.

40. Sugimoto T, Nishiyama K, Kuribayashi F, Chihara K: Serum levels of insulinlike growth factor (IGF) I, IGF-binding protein (IGFBP)-2, and IGFBP-3 in osteoporotic patients with and without spinal fractures. J Bone Miner Res 1997, 12:1272-1279.

41. Greer RM, Rogers MA, Bowling FG, Buntain HM, Harris M, Leong GM, et al: Australian children and adolescents with type 1 diabetes have low vitamin D levels. Med J Aust 2007, 187:59-60.

42. Moore C, Murphy MM, Keast DR, Holick MF: Vitamin D intake in the United States. J Am Diet Assoc 2004, 104:980-983.

doi:10.1186/1687-9856-2011-13

Cite this article as: Simmons et al:: Metabolic control and bone health

in adolescents with type 1 diabetes. International Journal of Pediatric

Endocrinology 2011 2011:13.

\section{Submit your next manuscript to BioMed Central} and take full advantage of:

- Convenient online submission

- Thorough peer review

- No space constraints or color figure charges

- Immediate publication on acceptance

- Inclusion in PubMed, CAS, Scopus and Google Scholar

- Research which is freely available for redistribution

Submit your manuscript at www.biomedcentral.com/submit 